\title{
OBITUÁRIO DO PESQUISADOR JOSÉ CONSOLIM
}

por Allan MarTins da SiLVA

(Ministério da Saúde, cedido para a Secretaria de Estado da Saúde do Paraná, Laboratório Central.)

Em 27 de setembro de 2021, o Estado do Paraná perdeu um dos seus entomologistas mais ilustre no campo da Saúde Pública, o Pesquisador José Consolim, que residia na cidade de Jacarezinho. O seu falecimento ocorreu logo após ter completado 96 anos de idade. Nasceu em 28 de outubro de 1925, no sítio conhecido na época por Anhumas, localizado no município de Ribeirão Claro, Paraná.

José Consolim, ou simplesmente "Consolim", como era conhecido entre os amigos de trabalho, ingressou na vida pública pelo Serviço Nacional de Malária. Por esta instituição realizou o curso para Pesquisador, um grupo seleto de entomologistas especializados em Anophelinae (Diptera: Culidiade), mosquitos de importância na epidemiologia da malária.

No final da década de 1940, juntamente com outros dois pesquisadores paranaenses, Dr. Mário Antônio Borba e Dr. Ênnio Luz, formou a equipe estadual que desenvolveu os estudos sobre a malária, realizado no norte do Paraná pelo médico sanitarista René Guimarães Rachou. Porém, os dois primeiros artigos em que o Consolim participou como coautor foram estudos sobre a esquistossomose no Paraná, com a descoberta de novos focos de transmissão da doença, em 1954, e a identificação de reservatórios silvestres de Schistosoma mansoni 
(Schistosomatidae) em área endêmica, em 1967.

José Consolim e o meu pai, Sebastião Martins da Silva, foram grandes amigos e trabalharam juntos nos inquéritos entomológicos realizados na primeira metade da década de 1950, no Povoado Marques dos Reis, município de Jacarezinho. Estes estudos entomológicos foram pioneiros e contribuíram para o combate da malária no sul do Brasil.

A partir de 1956 passou a integrar a equipe de pesquisadores do recém-criado Departamento Nacional de Endemias Rurais (DNERu), que tratava do controle de todas as endemias importante na época. $\mathrm{Na}$ segunda metade da década de 1960 foi convidado a fazer parte da estafe da Campanha de Erradicação da Malária (CEM), voltado exclusivamente para o controle dessa doença. Na década seguinte passa a atuar como entomólogo da Superintendência de Campanhas de Saúde Pública (Sucam).

Mas, José Consolim não atuou somente no norte do Paraná. Ele realizou pesquisas nos quatro cantos do Estado, incluindo o litoral, região do extremo oeste e o noroeste paranaense. A sua vida científica foi bastante profícua e possibilitou diversos estudos que contribuíram para o conhecimento, principalmente, da fauna anofélica do Paraná. O seu primeiro artigo foi publicado em 1973, dando início a uma série de estudos sobre os anofelíneos. Esta primeira obra "Densidade e Regime do Rio" tratou das investigações sobre a densidade dos anofelíneos no alto e médio curso do rio Paraná.

Outros dois estudos da série foram publicados em 1974, com os títulos "Comportamento do inseto em relação ao homem e à habitação" e "Comportamento do Anopheles rondoni". No mesmo ano publicou "Anopheles darlingi como vetor de malária no Estado do Mato Grosso" (atual Mato Grosso do Sul), relatando pela primeira vez no Estado o encontro desta espécie, naturalmente, infectada por plasmódio.

Ainda na década de 1970, Consolim participou de estudos relevantes sobre a fauna de mosquitos relacionada a malária-bromélia no litoral paranaense. Termo este utilizado para descrever a transmissão de plasmódios pelos Anopheles (Kerteszia), cujas formas imaturas se desenvolvem em plantas bromeliáceas. Estes estudos resultaram em artigos científicos que tratavam sobre o comportamento desses 
mosquitos, longevidade, suscetibilidade aos inseticidas e os aspectos da transmissão da malária no litoral.

No início da década de 1980, Consolim desenvolve um importante estudo sobre infecção experimental de anofelíneos, realizado em um posto avançado na Ilha Mutum, localizado no arquipélago fluvial rio Paraná. E compartilha uma publicação com seus colegas, sobre um achado atípico de formas imaturas de Anopheles (Kerteszia) em criadouros artificiais.

Na década de 1990, aposentado do Serviço Público, Consolim atuou como pesquisador convidado da Itaipu Binacional, junto ao Departamento de Meio Ambiente Social, Setor de Saúde Pública. Onde desenvolveu estudos sobre a fauna de flebotomíneos (Diptera: Psychodidae) ocorrente no entorno do Lago de Itaipu. Escreveu uma revisão de dados sobre Anopheles (Nyssorhynchus) darlingi Hoot 1926 e a malária no Lago de Itaipu. E complementa com a sua última obra "Culicídeos do Lago de Itaipú”.

Consolim foi um pesquisador dedicado e apaixonado pelo seu ofício. Seus estudos foram a base para desenvolvimento de novos métodos de trabalho e medidas para o controle de doenças. Estamos nos despedindo do Pesquisador Entomologista José Consolim. Mas, a sua obra permanece como um dos alicerces fortes no conhecimento das endemias rurais do Estado do Paraná.

\section{FONTESEOBRA REUNIDA}

Lobo, A. G. S.; E. Luz, E. \& J. Consolim. 1954. Novos focos de Esquistossomose mansônica no Estado do Paraná. Revta Brasil. Malariol. Doenças Trop. 6 (4): 555-565.

Luz, E.; E. C. Lima \& J. Consolim. 1967. Reservatórios silvestres de Schistosoma mansoni numa área endêmica de Esquistossomose mansônica no Estado do Paraná. An. Fac. Med. Univ. Par. 9-10 (12): 113-120.

Consolim, J. \& J. T. Galvão. 1973. Sobre os anofelino do Rio Paraná. I. Densidade e regime do rio. Arq. Biol.Tecn. 16: 174-181.

Consolim, J. 1974 a. Sobre os Anofelinos do Rio Paraná. II. Comportamento do inseto em relação ao ser humano e à habitação. Brazil. Arc. Biol. Tech. 17 (1): 24-29. 
Consolim, J. 1974 b. Sobre os anofelinos do Rio Paraná. III. Comportamento do Anopheles rondoni. Brazil. Arc. Biol. Tech. 17 (2): 113-114.

Consolim, J. 1974 c. Anopheles darlingi como vetor de malária no Estado de Mato Grosso. Brazil. Arc. Biol. Tech. 17 (2).

Luz, E.; J. Consolim; A. M. Vieira \& A. M. Borba. 1977. Sobre a longevidade de Anopheles cruzii em laboratório. Arq. Biol. Tecnol 20:31-33.

Borba, A. M.; J. Consolim; A. M. VIEIRA \& E. Luz. 1978. Alguns aspectos epidemiológicos da persistência de transmissão de malária no litoral paranaense. II - Quantidade de sangue ingerido por Anopheles cruzii (Diptera, Culicidae). Brazil. Arch. Biol. Tech. 21: 19-21.

Luz, E.; J. Consolim; A. M. VIEIRA \& A. M. Borba. 1979. Alguns aspectos epidemiológicos da persistência de transmissão de malária no litoral Paranaense. I. Idade Fisiológica de Anopheles cruzii (Diptera, Culicidae). Brazil. Arch. Biol. Tech. 22 (1): 63-88.

Consolim, J.; E. Luz; A. M. VieIRA, A. \& A. M. Borba. 1979 a. Alguns aspectos epidemiológicos sobre a persistência de transmissão de Malária no litoral Paranense. III. Entrada e permanência de Anopheles cruzii na habitação humana. Brazil. Arch. Biol. Tech. 22 (2): 173179.

Consolim, J.; A. M. BorbA; A. M. VIEIRA; E. Luz. 1979 b. Alguns aspectos epidemiológicos sobre a persistência de transmissão de malária no Litoral Paranense. IV - Suscetibilidade de Anopheles cruzii ao DDT. Brazil. Arch. Biol. Tech. 22 (2): 181-182.

Consolim, J. \& M. S. Fagundes. 1981. Sobre os Anofelinos do Rio Paraná. IV - Infecção experimental de 4 espécies com Plasmodium vivax. Brazil. Arch. Biol. Tech. 24 (4): 417-423.

Luz, E.; J. Consolim; O. C. Barbosa \& P. B. Torres. 1987. Larvas de Anopheles (Subgênero Kerteszia) Theobald 1905 encontradas em criadouros artificiais, no Estado do Paraná, Brasil. Revta Saúde Públ. 21 (5): 466-468.

Consolim, J.; E. Luz \& P. B. Torres. 1990. Flebotomíneos da área o reservatório da hidroelétrica de Itaipu, Estado do Paraná, Brasil (Diptera, Psychodidae). Cad. Saúde Públ. 6 (1): 86-89.

Consolim, J.; E. Luz; N. J. M. Pellegrini \& P. B. Torres. 1991. O Anopheles (Nyssorhynchus) darlingi Hoot, 1926 e a malária no Lago de Itaipu, Estado do Paraná, Brasil: uma revisão de dados (Diptera, Culicidae). Brazil. Arch. Biol. Tech. 34 (2): 263-286. 
Consolim, J.; N. J. M. Pellegrini \& E. Luz. 1993. Culicídeos (Diptera, Culicidae) do Lago de Itaipú, Paraná, Brasil. I. Município de Foz do Iguaçu. Acta Biológica Paranaense 22 (1,2,3,4): 83-90.

Recebido em 1 de outubro de 2021. 
